\title{
Gaze Palsy, Organomegaly, and Inspiratory Stridor: A Diagnostic Triad
}

\author{
Priyanka Madaan $^{1} \cdot$ Chandana Bhagwat $^{1} \cdot$ Shivan Kesavan $^{1} \cdot$ Lokesh Saini $^{1}$ (D) $\cdot$ Naveen Sankhyan $^{1}$
}

Received: 5 August 2020 / Accepted: 4 September 2020 / Published online: 11 September 2020

(C) Dr. K C Chaudhuri Foundation 2020

An 11-mo-old girl presented with developmental delay and squint (Supplementary file: Video 1). She was first-born to non-consanguineous healthy parents with a smooth perinatal transition. Examination revealed normal head size, central hypotonia, stridor, massive hepatosplenomegaly, and non-concomitant squint (Supplementary file: Video 1). Investigations revealed a normal brain MRI, pathologically increased chitotriosidase activity $(>1500 \mu \mathrm{mol} / \mathrm{L} / \mathrm{h}$; reference: $\leq 351.9 \mu \mathrm{mol} / \mathrm{L} / \mathrm{h})$ and reduced beta-glucocerebrosidase activity $(1.2 \mu \mathrm{mol} / \mathrm{L} / \mathrm{h}$; reference: $\geq 4.1 \mu \mathrm{mol} / \mathrm{L} / \mathrm{h}$ ). The child succumbed to aspiration pneumonia at 13 mo of age. Clinical exome sequencing confirmed the diagnosis [homozygous pathogenic variant-c.1448T $>$ C (p.Leu483Pro) in GBA gene]. Both parents were carriers and were advised antenatal counseling.

Acute neuronopathic Gaucher disease is an extremely rare storage disorder with an abysmal prognosis [1-3]. Its incidence accounts for nearly $5 \%$ of all patients with Gaucher disease [3]. The deficiency of glucocerebrosidase leads to the accumulation of glucosylceramides in the reticuloendothelial system and brainstem degeneration. The clinical suspicion is primarily based on pattern recognition. Organomegaly, gaze restriction, stridor, and recurrent apneas with relatively normal neuroimaging are sine qua non of acute neuronopathic Gaucher disease. Refractory seizures may occur later in the course of the disease [3]. Although squint is a common association of developmental delay, the importance of careful

Electronic supplementary material The online version of this article (https://doi.org/10.1007/s12098-020-03489-4) contains supplementary material, which is available to authorized users.

Lokesh Saini

drlokeshsaini@gmail.com

1 Pediatric Neurology Unit, Department of Pediatrics, Advanced Pediatric Centre, Post graduate Institute of Medical Education and Research, Chandigarh 160012, India ophthalmological examination for gaze restriction in children with developmental delays cannot be understated [4].

Acknowledgements Authors thank the parents of the patient for the images and adding to the literature.

\section{Compliance with Ethical Standards}

Conflict of Interest None.

Consent Written informed consent obtained from parents.

\section{References}

1. Kang L, Wang Y, Gao X, et al. Genotypes and phenotypes in 20 Chinese patients with type 2 Gaucher disease. Brain Dev. 2018;40: 876-83.

2. Mignot C, Doummar D, Maire I, De Villemeur TB. The French type 2 Gaucher disease study group. Type 2 Gaucher disease: 15 new cases and review of literature. Brain Dev. 2006;28:39-48.

3. Stirnemann J, Belmatoug N, Camou F, et al. A review of Gaucher disease pathophysiology, clinical presentation and treatments. Int J Mol Sci. 2017;18:441.

4. Madaan P, Reddy C, Saini L. Gaze palsy: an important diagnostic clue. J Pediatr. 2019;212:236.

Publisher's Note Springer Nature remains neutral with regard to jurisdictional claims in published maps and institutional affiliations. 